\title{
Association between physical performance and incidence of end-stage renal disease in older adults: a national wide cohort study
}

Hee-won Jung ${ }^{1+}$, In Young Choi ${ }^{2+}$, Dong Wook Shin ${ }^{2,3^{*}}$ (D) Kyungdo Han ${ }^{4}$, Jung Eun Yoo ${ }^{5}$, Sohyun Chun ${ }^{6}$ and Yongjin $\mathrm{Yi}^{7}$

\begin{abstract}
Background: Physical frailty has previously been associated with adverse clinical outcomes in patients with endstage renal disease (ESRD). This study aimed to determine whether impaired physical performance at baseline is associated with the incidence of ESRD, using a nationwide database.

Methods: The timed up-and-go (TUG) test was used to assess physical frailty in 1,552,781 66-year-old individuals, using health examination database records from the Korean National Health Insurance Service. As a primary endpoint, incident ESRD was defined operationally using healthcare claims data from the Korean Health Insurance Review and Assessment Service.

Results: Our results showed that baseline kidney function was significantly worse in individuals with TUG results of $>10$ s compared to individuals with an intact TUG performance ( $\leq 10 \mathrm{~s}$ ). Kaplan-Meier analysis showed a stepwise dose-response relationship between baseline physical performance and the incidence rate of ESRD (log-rank test $P$ value of $<0.001)$. An increasing ESRD incidence rate trend with poor physical performance remained significant after adjusting for characteristics such as baseline glomerular filtration rate and proteinuria.

Conclusion: Poor baseline physical performance was associated with an increased risk of ESRD, suggesting possible interactions between systemic frailty and vascular aging processes.
\end{abstract}

Keywords: Frailty, Physical function, Chronic kidney disease, Morbidity

\section{Background}

Due to global population aging and a rising number of patients with chronic multimorbidities such as diabetes mellitus (DM) and hypertension (HT), effective healthcare for patients with chronic kidney disease (CKD) has become more urgent. Globally, end-stage renal disease (ESRD), a state of advanced CKD requires either kidney

\footnotetext{
* Correspondence: dwshin.md@gmail.com

${ }^{\dagger}$ Hee-won Jung and In Young Choi contributed equally as first author.

${ }^{2}$ Total Healthcare Center, Kangbuk Samsung Hospital, B1, Samsung Main B/D, 67, Sejong-daero, Jung-gu, Seoul 04514, South Korea

${ }^{3}$ Department of Digital Health, SAIHST, Sungkyunkwan University, 81 Irwon-Ro, Gangnam-gu, Seoul 06351, South Korea

Full list of author information is available at the end of the article
}

transplantation or renal replacement therapy, has been shown to affect patient quality of life and lead to morbidity and mortality [1, 2]. A United States study estimated the cumulated lifetime risk of developing ESRD to be approximately $2 \%$ among individuals of European ethnicity and 7\% among those of AfricanAmerican ethnicity, when calculated at 20 years of age [3]. A recent study suggested that the lifetime incidence of ESRD at birth was 3.6\% in the United States [4]. Furthermore, treatment costs have been estimated to be considerably higher for patients with ESRD than for patients with common malignancies [3].

C C The Author(s). 2021 Open Access This article is licensed under a Creative Commons Attribution 4.0 International License, which permits use, sharing, adaptation, distribution and reproduction in any medium or format, as long as you give appropriate credit to the original author(s) and the source, provide a link to the Creative Commons licence, and indicate if changes were made. The images or other third party material in this article are included in the article's Creative Commons licence, unless indicated otherwise in a credit line to the material. If material is not included in the article's Creative Commons licence and your intended use is not permitted by statutory regulation or exceeds the permitted use, you will need to obtain permission directly from the copyright holder. To view a copy of this licence, visit http://creativecommons.org/licenses/by/4.0/ The Creative Commons Public Domain Dedication waiver (http://creativecommons.org/publicdomain/zero/1.0/) applies to the data made available in this article, unless otherwise stated in a credit line to the data. 
Worldwide, the causes of CKD vary considerably; however, chronic diseases such as DM and HT have been reported to be main causes of CKD in high- and middle-income countries [2]. These chronic diseases and metabolic risk factors, such as cigarette smoking and obesity, have been reported to be factors promoting glomerulosclerosis, which eventually leads to decreased kidney function [5]. Accelerated features of the aging phenotype, including vascular calcification, cachexia, and frailty, have been observed in relation to decreasing kidney function, suggesting cross-links between kidney function and systemic aging, especially given the vascular nature of the kidney $[6,7]$.

Frailty is a common geriatric syndrome and a marker of biological age that is defined as a state of decreased physiological reserve and increased vulnerabilities for possible stressors with aging, and is a well-known risk factor for morbidity, mortality, and functional decline in older adults $[8,9]$. Several studies have shown that frailty is associated with systemic inflammation and phenotypic vascular aging that commonly occurs with chronic diseases [10-13]. Furthermore, recent studies have suggested that reducing systemic inflammation associated with aging, both in an accelerated aging mice model and in naturally aged mice, can lead to an improvement in frailty in rodents $[14,15]$. These results suggest that frailty is a biological construct that may reflect the systemic aging status of organisms.

In patients with ESRD, one study reported that frailty was common in approximately $50 \%$ of study patients aged $\geq 65$ years old [16], and an even younger population with ESRD showed physical frailty [17]. A study from Korea reported that baseline frailty in patients with ESRD undergoing hemodialysis adversely affected composite outcomes including all-cause mortality and hospitalization [18]. Similarly, a study from the United States showed that frailty was associated with adverse outcomes in patients having undergone kidney transplantation $[17,19]$. To our knowledge, despite these outcomes and the significance of frailty, the role of frailty in the development of ESRD in older adults has not been reported to date. This study aimed to determine whether physical frailty measured using the timed 'up-and-go' (TUG) test at baseline was associated with the incidence of ESRD in Korean older adults aged 66 years who had participated in the National Screening Program for Transitional Ages (NSPTA).

\section{Methods}

\section{Study setting and population}

In this study, we used data derived from the Korean National Health Insurance Service (KNHIS) database. The KNHIS is a nationwide universal healthcare insurer that serves virtually the entire Korean population, comprising $96.9 \%$ of those paying into the insurance system and the underserved population that receives medical aid. This data is publicly available from https:// nhiss.nhis.or.kr/bd/ay/bdaya001iv.do.

The KNHIS database contains information on demographic factors, such as age, sex, death date, and the results of the national health screening program, as well as information on the utilization of medical facilities, International Classification of Diseases 10th Revision (ICD-10) codes, and reimbursement data for procedures and medicines prescribed in both outpatient and inpatient settings.

The NSPTA is a special part of the national health screening program for 66-year-old individuals that includes a geriatric assessment [20] in the National Health Screening Program (NHSP), which is provided by the KNHIS. The NSPTA consists of a health examination that is offered during a routine NHSP and includes a lifestyle assessment questionnaire, anthropometric measurements, and laboratory tests, as well as geriatric functional examinations for physical performance and cognitive function.

In this study, we analyzed NSPTA data from 2009 to 2015 involving a population of $1,852,792$ individuals. We excluded 238,865 individuals registered with the National Disability Registration System having a baseline disability (e.g. visual/hearing disability, mental/cognitive disability, and amputation or spinal cord injury) as they were unable to perform the TUG test. We excluded individuals with ESRD at baseline $(n=1363)$ or with a baseline estimated glomerular filtration rate (eGFR) of $<$ $15 \mathrm{~mL} / \mathrm{min} / 1.73 \mathrm{~m}^{2}(n=7544)$. Finally, we excluded individuals with missing TUG test records $(n=1363)$ or other covariables (e.g. smoking status, $n=26.304$ ), and the final study population comprised 1,552,781 individuals. This study was approved by the Institutional Review Board (IRB) of Samsung Medical Center (IRB number: SMC-2019-07-046). Informed consent requirement was waived by the Institutional Review Board because the data does not contain personal information. All methods were performed in accordance with the relevant guidelines and regulations.

\section{Assessments of physical frailty}

We used the TUG test to assess physical frailty. This test has previously been used as a basic functional assessment for vulnerability in older adults $[22,23]$ and correlates well with other frailty measures, including the 5-item Cardiovascular Health Study frailty scale score and Short Physical Performance Battery total score in the Korean population [24]. During the NSPTA, the TUG test was administered as part of the geriatric assessment in community-based clinics or hospitals using a standardized manual. Individuals were timed while they rose from a chair, walked at a comfortable 
pace to a line on the floor $3 \mathrm{~m}$ away, turned and walked back to the chair, and sat down again. Individuals were categorized into 4 groups according to their TUG test results, as follows: Group $1(<10 \mathrm{~s})$, Group 2 (10-14.9 s), Group 3 (15-19.9s), and Group 4 ( $\geq 20 \mathrm{~s})$.

\section{Measurements and definitions}

Cigarette smoking status was determined using a questionnaire and the responses were categorized as follows: non-smoker (never smoked), a past history of smoking, and active smoking. Alcohol consumption was categorized as follows: none $(0 \mathrm{~g} /$ day), mild to moderate $(<30 \mathrm{~g} /$ day $)$, and heavy ( $\geq 30 \mathrm{~g} /$ day). Regular exercise was defined as engaging in physical activity of moderate to vigorous intensity for $\geq 3$ days per week. Information concerning comorbidities and a history of falls was obtained from responses to the questionnaire. Information concerning income levels was derived from monthly insurance premiums, as insurance contributions are determined according to income levels and not according to health risk in Korea. Blood samples for the measurement of serum creatinine $(\mathrm{Cr})$, glucose, highdensity lipoprotein (HDL)-cholesterol, low-density lipoprotein (LDL)-cholesterol, total cholesterol, and triglyceride levels were drawn after an overnight fast and assessed at laboratories that met national standards.

In this study, eGFR was calculated using the abbreviated Modification of Diet in Renal Disease (MDRD) formula: $175 \times$ serum $\mathrm{Cr}(\mathrm{mg} / \mathrm{dL})^{-1.154} \times$ Age $(\mathrm{y})^{-0.203} \times(0.742$ if female) [25]. For sensitivity analysis, we also used the Chronic Kidney Disease Epidemiology Collaboration (CKD-EPI) equation based on serum $\mathrm{Cr}$ to calculate the eGFR [26]. The level of proteinuria was assessed using the dipstick method on midstream samples and was reported using the following grades: absent, trace $( \pm), 1+, 2+, 3+$, and $4+$ (corresponding to protein levels, as follows: undetectable, $10 \mathrm{mg} / \mathrm{dL}, 30 \mathrm{mg} / \mathrm{dL}, 100 \mathrm{mg} / \mathrm{dL}, 300 \mathrm{mg} /$ $\mathrm{dL}$, and $1000 \mathrm{mg} / \mathrm{dL}$, respectively), and meaningful proteinuria was defined as dipstick results of $\geq 1+$.

HT was defined as the presence of at least one claim within a 12-month period under ICD-10 codes I10-11, and a history of a prescribed antihypertensive agent, or a systolic blood pressure (BP) of $\geq 140 \mathrm{mmHg}$ or diastolic $\mathrm{BP}$ of $\geq 90 \mathrm{mmHg}$ at the time of examination. DM was defined as having at least $\geq 1$ record of International Statistical Classification of Diseases and Related Health Problems ICD codes E10-14 within a 12-month period, a history of prescription antidiabetic medication, or a fasting glucose level of $\geq 126 \mathrm{mg} / \mathrm{dL}$. The presence of dyslipidemia was defined as having at least one claim within a 12-month period under ICD-10 code E78, a history of having been prescribed a lipid-lowering agent, or a total cholesterol level $\geq 240 \mathrm{mg} / \mathrm{dL}$ at the time of examination.

\section{Outcome definition}

The primary endpoint of the study was incident ESRD, which was defined using combinations of the ICD 10th revision codes, namely, N18-19, Z49, Z94.0, and Z99.2, as recorded in the claims database, the presence of codes related to renal replacement therapies (KNHIS procedure codes O7011-O7020 or V001 for hemodialysis, O7071-O7075 or V003 for peritoneal dialysis), and/or receiving kidney transplantation (R3280) as recorded in the Korean Health Insurance Review and Assessment Service database.

\section{Statistical analysis}

The baseline characteristics of the population groups were compared according to the TUG test results using independent $\mathrm{t}$-tests for continuous variables and Chisquare tests for categorical variables. During the followup period starting from 2009, individuals were censored on the day of ESRD incidence, or on December 31, 2016, whichever occurred first. Incidence rates were expressed as cases per 1000 person-years. Kaplan-Meier curves were used to visualize group differences in ESRD incidence.

Hazard ratios (HRs) for the incidence of ESRD according to the TUG test groups were estimated using Cox proportional hazards regression analysis. Analysis was initially unadjusted (Model 1). We then included additional covariables, such as sex, lifestyle variables (cigarette smoking, alcohol consumption, physical activity levels, and income), in Model 2. We further adjusted for BMI and comorbidities including DM, HT, dyslipidemia, and baseline eGFR in Model 3. In Model 4, we further included the semi-quantitative status of proteinuria as a covariable in addition to variables listed in Model 3.

As individuals with low eGFR may have higher mortality than individuals with higher eGFR, and death may compete with ESRD incidence, we also performed sensitivity analysis by considering death as a competing event. The semiparametric proportional hazards model by Fine and Gray was implemented for this competing risk regression analysis [27].

Stratified analysis was performed according to baseline eGFR using both MDRD equations in 4 groups $(<30$ $\mathrm{mL} / \mathrm{min} / 1.73 \mathrm{~m}^{2}, \quad 30-60 \mathrm{~mL} / \mathrm{min} / 1.73 \mathrm{~m}^{2}, \quad 60-90 \mathrm{~mL} /$ $\mathrm{min} / 1.73 \mathrm{~m}^{2}$, and $\geq 90-\mathrm{mL} / \mathrm{min} / 1.73 \mathrm{~m}^{2}$ ). Sensitivity analysis was performed using different eGFR calculation methods, such as the CKD-EPI equation.

We considered two-tailed $P$-values of $<0.05$ statistically significant. All statistical analyses were performed using SAS software, version 9.4 (SAS Institute, Cary, NC, USA). 


\section{Results}

Baseline characteristics

Of 1,552,781 older adults aged 66 years, 694,239 (44.7\%) were men; 1,159,126 (74.6\%) had a TUG test result of < $10 \mathrm{~s}$, and 393,655 (25.4\%) had a TUG test result of $\geq 10 \mathrm{~s}$ (Table 1). The presence of comorbidities, such as DM, HT, dyslipidemia, history of stroke, and myocardial infarction, was associated with a higher TUG test result. Baseline CKD status and eGFR categories using the MDRD formula with serum $\mathrm{Cr}$ showed a statistically significant difference between the groups dichotomized according to the TUG test results. Metabolic parameters, such as BMI, weight circumference, BP, and total cholesterol, were significantly higher in those with a higher TUG test result.

\section{Incidence of ESRD according to TUG performance}

Figure 1 shows the cumulative incidence probability of ESRD during follow-up periods according to 4 TUG test performance categories. Using Kaplan-Meier curves, dose-response relationships between the incidence of ESRD and TUG performance categories were observed (log-rank test, $P<0.001$ ).

In multivariable analysis using Cox proportional hazard models (Table 2), we observed increasing incidence trends for ESRD with impaired performance in the TUG test. Compared to individuals with a TUG performance of $<10 \mathrm{~s}$, individuals with a higher TUG test result showed an increased risk of ESRD. In the fully adjusted model (Model 4), the adjusted HRs were 1.07 (95\% CI $1.00-1.15)$ in the 10-14.9 s TUG test group, 1.11 (95\% CI $0.96-1.30$ ) in the 15-19.9 s TUG test group, and 1.45 (95\% CI 1.08-1.95) in the $>20 \mathrm{~s}$ TUG test group. The overall increasing incidence trends for ESRD with impaired performance on the TUG test were maintained with the competing risk model.

\section{Stratified and sensitivity analyses}

Generally, increased incidence rate trends for ESRD with a poor TUG test performance were maintained in the stratified analysis according to varying baseline eGFR using the MDRD formula (Table 3). Moreover, these trends were maintained even in stratified analysis using eGFR based on CKD-EPI equations (Table 4).

\section{Discussion}

In this study, we found that baseline TUG performance was associated with a future incidence risk of ESRD in a dose-dependent manner among individuals in a large-scale 66-year-old Korean sample population. To our knowledge, this is the first study to show an association between physical frailty and the progression of CKD.

The association of impaired physical performance at baseline and the increasing incidence of ESRD might be explained through several pathophysiological mechanisms. ESRD is a well-recognized end phenotype of vascular aging pathology and inflammation that might be related to life-long cumulative exposure to metabolic stressors related to epigenetic (i.e. lifestyle) factors [6, 28, 29]. Cumulative evidence from basic research and clinical studies suggest that lifestyle-related chronic diseases are associated with both CKD progression and aging phenotypes, including frailty and cognitive dysfunction $[6,7,30]$. This inference is in accordance with that of a previous cross-sectional study using National Health and Nutrition Examination Survey (NHANES) subpopulation data that showed an association between lower physical activity levels and reduced kidney function [31]. Moreover, individuals in our study with a poor TUG test performance at examination had a higher burden of chronic metabolic diseases, and therefore, might have a higher degree of systemic aging than individuals with better TUG test performances, leading consequently to a higher incidence of ESRD during follow-up.

Although not evaluated in the present study, polypharmacy, a common geriatric syndrome defined as taking multiple medications, is frequently observed in older patients treated for multimorbidity. Polypharmacy might have contributed to worsening kidney function during the follow-up period [32]. The Atherosclerosis Risk in Communities cross-sectional study showed that frailty and polypharmacy were associated with reduced kidney function [33]. The association between polypharmacy and lower kidney function has been similarly observed in another cross-sectional study analyzing NHANES data [34]. In accordance with these study findings and, as physical frailty has been shown to overlap with multimorbidity and disabilities [9], impaired baseline physical performance determined as prolonged TUG result may imply a higher chronic disease burden and medication exposure of the kidneys.

Previous studies have shown associations between vascular aging phenotypes, such as small vessel disease and retinal vessel abnormalities, and physical performance $[13,35]$, which, in turn, support studies that have shown the effects of baseline frailty in patients with ESRD on clinical adverse outcomes [16, 17, 19], and associations between physical performance and the degree of CKD [36]. However, in our results, an impaired TUG performance increased the incidence of future ESRD, even in individuals with a GFR of $60-90 \mathrm{~mL} / \mathrm{min}$, suggesting life-long accumulation of subclinical interactions between the aging process and polypharmacy with multimorbidity and physical frailty.

Based on our findings, when managing older patients with CKD, it might be beneficial to incorporate physical performance and frailty status assessment in clinical practice, either for risk prediction or as a preventive 
Table 1 Baseline characteristics of study population

\begin{tabular}{|c|c|c|c|c|c|}
\hline \multirow[t]{3}{*}{$n$} & \multicolumn{4}{|c|}{ Groups according to the TUG test results } & \multirow[t]{3}{*}{$P$-value } \\
\hline & $<10 \mathrm{~s}$ & $10-14.9 \mathrm{~s}$ & $15-19.9 \mathrm{~s}$ & $\geq 20 \mathrm{~s}$ & \\
\hline & \multicolumn{2}{|l|}{$1,159,126$} & \multicolumn{2}{|l|}{393,655} & \\
\hline Sex, male & $536,331(46.3)$ & $138,662(40.8)$ & $16,636(36.4)$ & $2610(33.9)$ & $<.0001$ \\
\hline \multicolumn{5}{|l|}{ Cigarette smoking } & $<.0001$ \\
\hline Non-smoker & $801,370(69.1)$ & $247,511(72.7)$ & $34,139(74.7)$ & $5842(75.9)$ & \\
\hline Past history of smoking & $216,258(18.7)$ & $52,169(15.3)$ & $6249(13.7)$ & $1018(13.2)$ & \\
\hline Active smoker & $141,498(12.2)$ & $40,596(11.9)$ & $5296(11.6)$ & $835(10.9)$ & \\
\hline \multicolumn{5}{|l|}{ Alcohol consumption } & $<.0001$ \\
\hline None & $820,995(70.8)$ & $250,469(73.6)$ & $34,726(76.0)$ & $6046(78.6)$ & \\
\hline Mild & $283,425(24.5)$ & $74,619(21.9)$ & $9127(20.0)$ & $1365(17.7)$ & \\
\hline Heavy & $54,706(4.7)$ & $15,188(4.5)$ & $1831(4.0)$ & $284(3.7)$ & \\
\hline Regular exercise, Yes & $301,620(26.0)$ & $80,237(23.6)$ & $10,031(22.0)$ & $1516(19.7)$ & $<.0001$ \\
\hline \multicolumn{5}{|l|}{ Income } & $<.0001$ \\
\hline Q1 (lowest) & $321,817(27.8)$ & $97,320(28.6)$ & $13,676(29.9)$ & $2452(31.9)$ & \\
\hline Q2 & 225,044 (19.4) & $66,378(19.5)$ & 8921 (19.5) & $1543(20.1)$ & \\
\hline Q3 & $304,506(26.3)$ & $90,793(26.7)$ & $12,050(26.4)$ & $1931(25.1)$ & \\
\hline Q4 (highest) & $307,759(26.6)$ & $85,785(25.2)$ & $11,037(24.2)$ & $1769(23.0)$ & \\
\hline \multicolumn{6}{|l|}{ Comorbidity } \\
\hline Dyslipidemia & $444,344(38.3)$ & $135,290(39.8)$ & $18,430(40.3)$ & $3169(41.2)$ & $<.0001$ \\
\hline Diabetes mellitus & 223,381 (19.3) & $70,836(20.8)$ & $10,206(22.3)$ & $1891(24.6)$ & $<.0001$ \\
\hline Hypertension & $599,132(51.7)$ & $185,989(54.7)$ & $26,200(57.4)$ & $4513(58.7)$ & $<.0001$ \\
\hline History of Ml & $9391(0.8)$ & $2885(0.9)$ & $410(0.9)$ & $116(1.5)$ & $<.0001$ \\
\hline History of stroke & $41,371(3.6)$ & $14,271(4.2)$ & $2291(5.0)$ & $596(7.8)$ & $<.0001$ \\
\hline CKD & $115,893(10.0)$ & $37,670(11.1)$ & $5622(12.3)$ & $1086(14.1)$ & $<.0001$ \\
\hline eGFR (using MDRD, $\mathrm{mL} / \mathrm{min} / 1.73 \mathrm{~m}^{2}$ ) & $84.7 \pm 36.1$ & $86.0 \pm 36.2$ & $85.0 \pm 31.2$ & $84.7 \pm 41.3$ & $<.0001$ \\
\hline $15-29$ & $1713(0.2)$ & $627(0.2)$ & $112(0.3)$ & $33(0.4)$ & $<.0001$ \\
\hline $30-59$ & $114,180(9.9)$ & $37,043(10.9)$ & $5510(12.1)$ & $1053(13.7)$ & \\
\hline $60-89$ & $798,406(68.9)$ & $219,894(64.6)$ & $29,361(64.3)$ & $4851(63.0)$ & \\
\hline$\geq 90$ & $244,827(21.1)$ & $82,712(24.3)$ & $10,701(23.4)$ & $1758(22.9)$ & \\
\hline \multicolumn{5}{|l|}{ Proteinuria } & $<.0001$ \\
\hline Absent & $1098,130(94.7)$ & $320,451(94.2)$ & $42,752(93.6)$ & $7141(92.8)$ & \\
\hline \pm (trace) & $27,503(2.4)$ & $9018(2.7)$ & $1267(2.8)$ & $246(3.2)$ & \\
\hline $1+$ & $21,370(1.8)$ & $6882(2.0)$ & $1032(2.3)$ & $183(2.4)$ & \\
\hline $2+$ & $9054(0.8)$ & $2821(0.8)$ & $430(0.9)$ & $83(1.1)$ & \\
\hline $3+$ & $2543(0.2)$ & $913(0.3)$ & $162(0.4)$ & $37(0.5)$ & \\
\hline $4+$ & $526(0.1)$ & $191(0.1)$ & $41(0.1)$ & $5(0.1)$ & \\
\hline BMI (kg/m2) & $24.2 \pm 2.9$ & $24.4 \pm 3.1$ & $24.6 \pm 3.3$ & $24.6 \pm 3.5$ & $<.0001$ \\
\hline Waist circumference $(\mathrm{cm})$ & $82.8 \pm 8.2$ & $83.1 \pm 8.3$ & $83.6 \pm 8.5$ & $83.8 \pm 8.9$ & $<.0001$ \\
\hline SBP $(\mathrm{mmHg})$ & $127.7 \pm 15.0$ & $128.4 \pm 15.2$ & $129.1 \pm 15.6$ & $128.8 \pm 16.0$ & $<.0001$ \\
\hline $\mathrm{DBP}(\mathrm{mmHg})$ & $77.4 \pm 9.6$ & $77.7 \pm 9.7$ & $78.1 \pm 9.9$ & $78.3 \pm 10.1$ & $<.0001$ \\
\hline Serum glucose (mg/dL) & $103.8 \pm 25.0$ & $104.0 \pm 26.5$ & $104.4 \pm 27.6$ & $105.8 \pm 29.8$ & $<.0001$ \\
\hline HDL cholesterol (mg/dL) & $53.8 \pm 15.4$ & $54.0 \pm 16.4$ & $54.3 \pm 19.6$ & $53.2 \pm 14.2$ & $<.0001$ \\
\hline LDL cholesterol (mg/dL) & $116.3 \pm 38.7$ & $116.2 \pm 39.5$ & $116.0 \pm 38.8$ & $116.8 \pm 40.5$ & 0.4956 \\
\hline Total cholesterol (mg/dL) & $196.1 \pm 38.4$ & $197.0 \pm 39.1$ & $197.4 \pm 40.0$ & $197.7 \pm 41.2$ & $<.0001$ \\
\hline
\end{tabular}


Table 1 Baseline characteristics of study population (Continued)

\begin{tabular}{|c|c|c|c|c|c|}
\hline \multirow[t]{3}{*}{ n } & \multicolumn{4}{|c|}{ Groups according to the TUG test results } & \multirow[t]{3}{*}{$P$-value } \\
\hline & $<10 \mathrm{~s}$ & $10-14.9 \mathrm{~s}$ & $15-19.9 \mathrm{~s}$ & $\geq 20 \mathrm{~s}$ & \\
\hline & $1,159,126$ & & 393,655 & & \\
\hline TUG (sec) & $7.2 \pm 1.5$ & $10.6 \pm 1.1$ & $16.0 \pm 1.3$ & $25.6 \pm 12.2$ & $<.0001$ \\
\hline Follow-up duration (year) & $5.0 \pm 2.0$ & $5.3 \pm 2.1$ & $5.6 \pm 2.1$ & $5.5 \pm 2.1$ & $<.0001$ \\
\hline
\end{tabular}

Data shown as number (percent) or mean \pm (standard deviation)

$B M I$ body mass index, $C K D$ chronic kidney disease, $D B P$ diastolic blood pressure, eGFR estimated glomerular filtration rate, $H D L$ high-density lipoprotein, $L D L$ lowdensity lipoprotein, MI myocardial infarction, MDRD Modification of Diet in Renal Disease, SBP systolic blood pressure, TUG timed up-and-go test

measure for adverse outcomes. In addition to addressing frailty only as a risk factor, several studies have reported that physical frailty can be improved with structured physical activity programs or multicomponent intervention programs [37-39]. Through combining previous results concerning the relevance of frailty in patients with CKD in our study findings, a specifically designed multicomponent intervention with tailored care for patients with CKD and comorbidities may show improved clinical outcomes in this population.

In this study, the TUG test was used as a measure for physical performance to determine physical frailty. Despite the presence of the floor effect and difficulties in separating components of gait or balance from the overall score, the TUG test has been validated as a reliable measure of mobility and cognitive impairment [40]. The TUG test has been proposed as a measure of physical

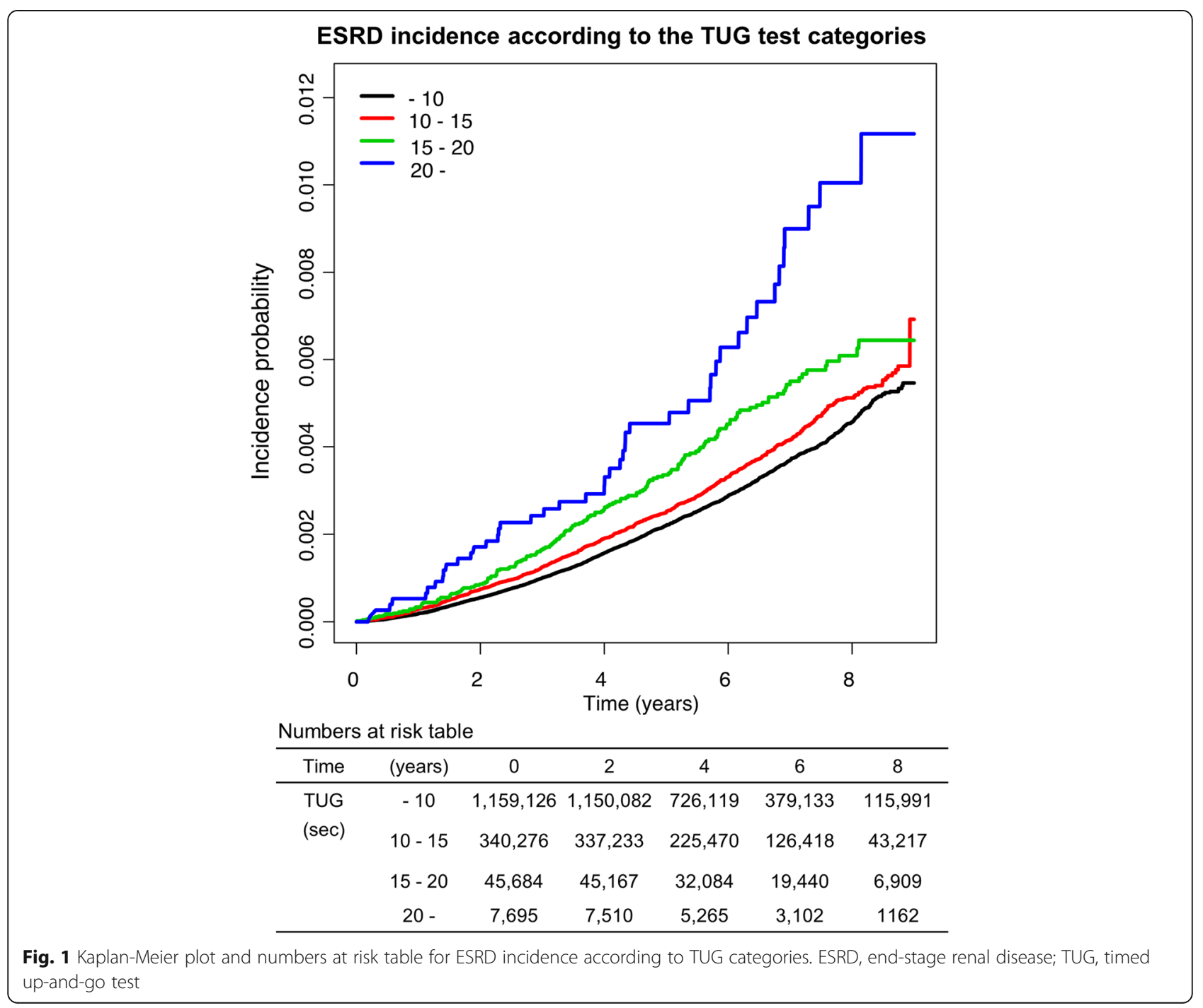


Table 2 Incidence of ESRD with TUG categories

\begin{tabular}{lllllllll}
\hline TUG & Subjects & $\begin{array}{l}\text { ESRD } \\
\text { incidence }\end{array}$ & Incidence rate ${ }^{\mathbf{a}}$ & Model $\mathbf{1}$ & Model 2 & Model 3 & Model 4 & $\begin{array}{c}\text { Competing } \\
\text { risk model }\end{array}$ \\
\hline$<10$ & $1,159,126$ & 2732 & 0.47 & 1 (ref.) & 1 (ref.) & 1 (ref.) & 1 (ref.) & 1 (ref.) \\
$\geq 10$ & 393,655 & 1206 & 0.59 & $1.21(1.13-1.33)$ & $1.25(1.16-1.33)$ & $1.10(1.02-1.17)$ & $1.09(1.12-1.17)$ & $1.07(1.00-1.15)$ \\
$<10$ & $1,159,126$ & 2732 & 0.47 & 1 (ref.) & 1 (ref.) & 1 (ref.) & 1 (ref.) & $1($ ref.) \\
$10-14.9$ & 340,276 & 984 & 0.55 & $1.15(1.07-1.24)$ & $1.18(1.10-1.27)$ & $1.07(0.99-1.15)$ & $1.07(1.00-1.16)$ & $1.07(0.99-1.15)$ \\
$15-19.9$ & 45,684 & 177 & 0.71 & $1.46(1.25-1.69)$ & $1.51(1.29-1.75)$ & $1.19(1.02-1.38)$ & $1.11(0.96-1.30)$ & $1.08(0.92-1.26)$ \\
$\geq 20$ & 7695 & 45 & 1.10 & $2.25(1.68-3.02)$ & $2.34(1.74-3.14)$ & $1.47(1.10-1.98)$ & $1.45(1.08-1.95)$ & $1.25(0.91-1.73)$ \\
\hline
\end{tabular}

Model 1: crude model; Model 2: adjusting for sex, smoking status, alcohol history, exercise level, and income; Model 3: adjusting for variables of Model 2 with BMI, $\mathrm{DM}, \mathrm{HT}$, dyslipidemia, and eGFR; Model 4: adjusting for variables of Model 3 and state of dipstick proteinuria (4 categories); Competing risk model: adjusting for variables in Model 4 and considering competing risk

$B M I$ body mass index, DM diabetes mellitus, eGFR estimated glomerular filtration rate using the abbreviated Modification of Diet in Renal Disease formula, ESRD end-stage renal disease, HT hypertension, TUG timed up-and-go test

${ }^{\text {aper }} 1000$ people

performance, which has been defined as objectively measured whole-body function related to locomotion in the recently updated European Working Guideline for Sarcopenia in Older People (EWGSOP2) [41]. Bischoff et al. [42] found that $92 \%$ of community-dwelling older women aged $65-85$ years were able to perform the test in $\leq 12 \mathrm{~s}$. In the EWGSOP2, TUG test of $\geq 20 \mathrm{~s}$ was suggested as a criterion for impaired physical performance. In our study, we categorized TUG test performance into to 4 groups, to evaluate the dose-response effect of TUG time on the incidence of ESRD.
This study was a nationwide, large, unselected population study of Korean older adults; however, it had some limitations. First, causality could not be determined in our observational study. While the associations were maintained, even after adjusting for eGFR as a continuous variable and the state of proteinuria in multivariable analysis, possibilities of reverse causality that impaired the TUG test results as consequences of increased CKD progression might have been reduced. Second, we used the eGFR based on serum $\mathrm{Cr}$ in this study, a biomarker that is processed in skeletal muscle, hence affected by skeletal muscle mass $[43,44]$. Since muscle mass is

Table 3 Stratified analysis of ESRD incidence according to baseline eGFR and TUG categories

\begin{tabular}{|c|c|c|c|c|c|c|c|c|c|}
\hline eGFR (MDRD) & TUG & Subjects & $\begin{array}{l}\text { ESRD } \\
\text { incidence }\end{array}$ & $\begin{array}{l}\text { Incidence } \\
\text { ratio }^{a}\end{array}$ & Model 1 & Model 2 & Model 3 & Model 4 & $\begin{array}{l}\text { Competing } \\
\text { risk model }\end{array}$ \\
\hline \multirow[t]{4}{*}{$15-29$} & -10 & 1713 & 659 & 104.26 & 1 (ref.) & 1 (ref.) & 1 (ref.) & 1 (ref.) & 1 (ref.) \\
\hline & $10-14.9$ & 627 & 223 & 97.53 & $0.94(0.81-1.09)$ & $0.98(0.84-1.14)$ & $0.96(0.82-1.11)$ & $0.99(0.85-1.15)$ & $0.96(0.82-1.12)$ \\
\hline & $151-9.9$ & 112 & 52 & 124.65 & $1.20(0.90-1.59)$ & $1.32(0.99-1.75)$ & $1.26(0.95-1.68)$ & $1.19(0.89-1.58)$ & $1.12(0.86-1.47)$ \\
\hline & $20-$ & 33 & 11 & 105.54 & $1.02(0.56-1.86)$ & $1.32(0.73-2.40)$ & $1.12(0.62-2.05)$ & $1.41(0.78-2.58)$ & $0.76(0.37-1.58)$ \\
\hline \multirow[t]{4}{*}{$30-59$} & -10 & 114,180 & 1120 & 1.89 & 1 (ref.) & 1 (ref.) & 1 (ref.) & 1 (ref.) & 1 (ref.) \\
\hline & $10-14.9$ & 37,043 & 413 & 2.04 & $1.05(0.93-1.17)$ & $1.12(1.00-1.25)$ & $1.02(0.91-1.14)$ & $1.04(0.93-1.16)$ & $1.03(0.92-1.16)$ \\
\hline & $15-19.9$ & 5510 & 71 & 2.25 & $1.13(0.89-1.44)$ & $1.22(0.96-1.56)$ & $1.03(0.81-1.32)$ & $0.97(0.76-1.23)$ & $0.93(0.72-1.21)$ \\
\hline & $20-$ & 1053 & 16 & 2.72 & $1.37(0.84-2.25)$ & $1.55(0.95-2.55)$ & $1.08(0.66-1.77)$ & $1.00(0.61-1.64)$ & $0.94(0.56-1.58)$ \\
\hline \multirow[t]{4}{*}{$60-89$} & -10 & 798,406 & 802 & 0.20 & 1 (ref.) & 1 (ref.) & 1 (ref.) & 1 (ref.) & 1 (ref.) \\
\hline & $10-14.9$ & 219,894 & 284 & 0.25 & $1.19(1.04-1.36)$ & $1.21(1.05-1.38)$ & $1.16(1.01-1.33)$ & $1.13(0.99-1.30)$ & $1.11(0.97-1.28)$ \\
\hline & $15-9.9$ & 29,361 & 48 & 0.30 & $1.38(1.03-1.85)$ & $1.40(1.04-1.87)$ & $1.31(0.97-1.75)$ & $1.24(0.93-1.66)$ & $1.22(0.90-1.64)$ \\
\hline & $20-$ & 4851 & 15 & 0.57 & $2.67(1.60-4.46)$ & $2.71(1.63-4.53)$ & $2.41(1.44-4.01)$ & $2.15(1.29-3.59)$ & $2.09(1.25-3.50)$ \\
\hline \multirow[t]{4}{*}{$\geq 90$} & -10 & 244,827 & 151 & 0.13 & 1 (ref.) & 1 (ref.) & 1 (ref.) & 1 (ref.) & 1 (ref.) \\
\hline & $10-14.9$ & 82,712 & 64 & 0.15 & $1.18(0.88-1.57)$ & $1.20(0.89-1.60)$ & $1.17(0.87-1.57)$ & $1.16(0.87-1.55)$ & $1.15(0.86-1.56)$ \\
\hline & $15-19.9$ & 10,701 & 6 & 0.11 & $0.83(0.37-1.88)$ & $0.86(0.38-1.94)$ & $0.81(0.36-1.82)$ & $0.81(0.36-1.83)$ & $0.83(0.37-1.87)$ \\
\hline & $20-$ & 1758 & 3 & 0.34 & $2.59(0.82-8.11)$ & $2.66(0.85-8.36)$ & $2.53(0.81-7.93)$ & $2.52(0.80-7.90)$ & $2.48(0.79-7.79)$ \\
\hline
\end{tabular}

Model 1: crude model; Model 2: Adjusting for sex, smoking status, alcohol history, exercise level, and income; Model 3: adjusting for variables of Model 2 with BMI, DM, HT, dyslipidemia, and eGFR; Model 4: adjusting for variables of Model 3 and state of dipstick proteinuria (4 categories); Competing risk model: adjusting for variables in Model 4 and considering competing risk

$B M I$ body mass index, DM diabetes mellitus, eGFR estimated glomerular filtration rate using the abbreviated Modification of Diet in Renal Disease formula, ESRD end-stage renal disease, $H T$ hypertension, TUG timed up-and-go test

${ }^{\text {a }}$ Per 1000 person-years 
Table 4 ESRD incidence according to baseline eGFR and TUG categories, using the CKD-EPI eGFR formula

\begin{tabular}{|c|c|c|c|c|c|c|c|c|}
\hline eGFR (CKD-EPI) & TUG & Subjects & ESRD incidence & Incidence ratio ${ }^{a}$ & Model 1 & Model 2 & Model 3 & Model 4 \\
\hline \multirow[t]{4}{*}{$15-29$} & -10 & 1868 & 699 & 101.09 & 1 (ref.) & 1 (ref.) & 1 (ref.) & 1 (ref.) \\
\hline & $10-14.9$ & 671 & 239 & 97.19 & $0.96(0.82-1.12)$ & $1.00(0.87-1.16)$ & $0.98(0.84-1.13)$ & $1.2(0.88-1.18)$ \\
\hline & $15-19.9$ & 125 & 55 & 115.72 & $1.14(0.87-1.50)$ & $1.20(0.91-1.58)$ & $1.21(0.92-1.60)$ & $1.17(0.88-1.54)$ \\
\hline & $20-$ & 34 & 11 & 102.72 & $1.03(0.57-1.87)$ & $1.28(0.70-2.33)$ & $1.11(0.61-2.02)$ & $1.43(0.78-2.60)$ \\
\hline \multirow[t]{4}{*}{ 30-59 } & -10 & 114,006 & 1078 & 1.82 & 1 (ref.) & 1 (ref.) & 1 (ref.) & 1 (ref.) \\
\hline & $10-14.9$ & 36,997 & 397 & 1.96 & $1.04(0.93-1.17)$ & $1.11(0.99-1.25)$ & $1.02(0.91-1.14)$ & $1.02(0.91-1.15)$ \\
\hline & $15-19.9$ & 5496 & 68 & 2.16 & $1.12(0.88-1.43)$ & $1.21(0.95-1.55)$ & $1.07(0.84-1.37)$ & $0.97(0.76-1.24)$ \\
\hline & $20-$ & 1052 & 16 & 2.72 & $1.42(0.87-2.33)$ & $1.60(0.97-2.61)$ & $1.10(0.67-1.80)$ & $1.00(0.61-1.64)$ \\
\hline \multirow[t]{4}{*}{ 60-89 } & -10 & 643,658 & 710 & 0.22 & 1 (ref.) & 1 (ref.) & 1 (ref.) & 1 (ref.) \\
\hline & $10-14.9$ & 171,381 & 246 & 0.27 & $1.20(1.04-1.39)$ & $1.21(1.04-1.40)$ & $1.16(1.00-1.34)$ & $1.13(0.98-1.31)$ \\
\hline & $15-19.9$ & 22,505 & 43 & 0.34 & $1.45(1.07-1.98)$ & $1.46(1.07-1.98)$ & $1.36(1.00-1.85)$ & $1.29(0.95-1.75)$ \\
\hline & $20-$ & 3684 & 13 & 0.64 & $2.72(1.57-4.71)$ & $2.74(1.58-4.74)$ & $2.43(1.41-4.22)$ & $2.13(1.23-3.70)$ \\
\hline \multirow[t]{4}{*}{$\geq 90$} & -10 & 399,594 & 245 & 0.13 & 1 (ref.) & 1 (ref.) & 1 (ref.) & 1 (ref.) \\
\hline & $10-14.9$ & 131,227 & 102 & 0.15 & $1.18(0.94-1.49)$ & $1.18(0.94-1.49)$ & $1.15(0.91-1.44)$ & $1.13(0.90-1.43)$ \\
\hline & 15-19.9 & 17,558 & 11 & 0.12 & $0.92(0.50-1.68)$ & $0.92(0.50-1.68)$ & $0.87(0.47-1.58)$ & $0.86(0.47-1.57)$ \\
\hline & $20-$ & 2925 & 5 & 0.34 & $2.60(1.07-6.30)$ & $2.56(1.06-6.21)$ & $2.37(0.98-5.74)$ & $2.39(0.99-5.80)$ \\
\hline
\end{tabular}

Model 1: crude model; Model 2: adjusting for sex, smoking status, alcohol history, exercise level, and income; Model 3: adjusting for variables of Model 2 with BMI, DM, HT, dyslipidemia, and eGFR; Model 4: adjusting for variables of Model 3 and state of dipstick proteinuria (4 categories)

$B M I$ body mass index, CKD-EPI Chronic Kidney Disease Epidemiology Collaboration equation based on serum creatinine, DM diabetes mellitus, eGFR estimated glomerular filtration rate, ESRD end-stage renal disease, $H T$ hypertension, TUG timed up-and-go test

${ }^{\text {aPer }} 1000$ person-years

correlated with muscle performance, and decreased muscle mass tends to result in a higher eGFR, it is possible that the association between decreased physical performance and a lower eGFR might have been diluted owing to the use of the eGFR value based on serum $\mathrm{Cr}$. This may have in turn resulted in an incomplete adjustment of the baseline eGFR in our multivariable analysis. We used the CKD-EPI formula to assess the sensitivity of the MDRD formula; however, further assessments using a cystatin C-based eGFR, which we could not conduct using the current dataset, may resolve this weakness. Third, we relied on the TUG test results; however, we could not distinguish domains of physical performance, such as gait speed or grip strength to further assess component-specific relevance. Further studies using more detailed measures such as a short physical performance battery may reveal more information concerning this issue. Fourth, while we attempted to consider possible risk factors and diseases that might have affected renal function in our analyses, there might be unadjusted confounders that were not available in the NHIS database. Lastly, although the risk of ESRD was 1.45 times higher in the $\geq 20 \mathrm{~s}$ TUG test group compared to that in the $<10 \mathrm{~s}$ TUG test group, the absolute risk difference was notably low (<1 per 1000 person-years) because of the low incidence rate of ESRD. While our data add evidence for the pathophysiological link between frailty and renal function, the clinical significance and utility of the TUG test in terms of renal care should be evaluated in further studies.

\section{Conclusions}

In conclusion, using nationwide population-based examination data and prospective outcomes derived from claims data, we found that a poor TUG performance was associated with an increased risk in the incidence of ESRD, suggesting possible interactions between systemic frailty and vascular aging processes. Further research is warranted to determine whether a structured multicomponent intervention to prevent the progression of frailty in older patients with CKD can improve clinical outcomes.

\section{Abbreviations}

BP: Blood pressure; CKD: Chronic kidney disease; CKD-EPI: Chronic kidney disease epidemiology collaboration; Cr: Creatinine; DM: Diabetes mellitus; ESRD: End-stage renal disease; eGFR: Estimated glomerular filtration rate; HRs: Hazard ratios; HDL: High-density lipoprotein; HT: Hypertension; ICD10: International classification of diseases 10th revision; IRB: Institutional review board; KNHIS: Korean national health insurance service; LDL: lowdensity lipoprotein; NHANES: National health and nutrition examination survey; NHSP: National health screening program; NSPTA: National screening program for transitional ages; MDRD: Modification of diet in renal disease; TUG: Timed up-and-go

\section{Acknowledgements \\ None.}

Authors' contributions

$\mathrm{HJ}$ and IYC contributed equally as first author. They were major contributors in writing the manuscript. DWS design and analyzed this study and interpreted the results. $\mathrm{KH}$ analyzed and interpreted the data. JEY, SC, and YY 
read the manuscript critically and actively revise it. All authors read and approved the final manuscript.

\section{Funding}

None.

\section{Availability of data and materials}

The datasets analysed during the current study are available in the Korean National Health Insurance Sharing Service (NHISS) repository, https://nhiss. nhis.or.kr/bd/ay/bdaya001iv.do.

\section{Declarations}

\section{Ethics approval and consent to participate}

This study was approved by the Institutional Review Board (IRB) of Samsung Medical Center (IRB number: SMC-2019-07-046). Informed consent requirement was waived by the Institutional Review Board because the data does not contain personal information.

\section{Consent for publication}

Not applicable.

\section{Competing interests}

The authors declare that they have no competing interests.

\section{Author details}

'Division of Geriatrics, Department of Internal Medicine, Asan Medical Center, University of Ulsan College of Medicine, Seoul, South Korea. ${ }^{2}$ Total Healthcare Center, Kangbuk Samsung Hospital, B1, Samsung Main B/D, 67, Sejong-daero, Jung-gu, Seoul 04514, South Korea. ${ }^{3}$ Department of Digital Health, SAIHST, Sungkyunkwan University, 81 Irwon-Ro, Gangnam-gu, Seoul 06351, South Korea. ${ }^{4}$ Department of Statistics and Actuarial Science, Soongsil University, Seoul, South Korea. ${ }^{5}$ Department of Family Medicine, Healthcare system Gangnam Center, Seoul National University Hospital, Seoul, South Korea. ${ }^{6}$ International Healthcare Center, Samsung Medical Center, Seoul, South Korea. ${ }^{7}$ Division of Nephrology, Dankook University Hospital, Cheonan-si, Chungcheongnam-do, South Korea.

\section{Received: 25 October 2020 Accepted: 2 March 2021}

\section{Published online: 10 March 2021}

\section{References}

1. Eckardt KU, Coresh J, Devuyst O, Johnson RJ, Kottgen A, Levey AS, Levin A. Evolving importance of kidney disease: from subspecialty to global health burden. Lancet. 2013;382(9887):158-69.

2. Webster AC, Nagler EV, Morton RL, Masson P. Chronic kidney disease. Lancet. 2017;389(10075):1238-52.

3. Kiberd BA, Clase CM. Cumulative risk for developing end-stage renal disease in the US population. J Am Soc Nephrol. 2002;13(6):1635-44.

4. Grams ME, Chow EK, Segev DL, Coresh J. Lifetime incidence of CKD stages 3-5 in the United States. Am J Kidney Dis. 2013;62(2):245-52.

5. Rule AD, Semret MH, Amer H, Cornell LD, Taler SJ, Lieske JC, Melton LJ III, Stegall MD, Textor SC, Kremers WK. Association of kidney function and metabolic risk factors with density of glomeruli on renal biopsy samples from living donors. In: Mayo Clinic Proceedings: Elsevier; 2011. p. 282-90.

6. Kooman JP, Dekker MJ, Usvyat LA, Kotanko P, van der Sande FM, Schalkwijk CG, Shiels PG, Stenvinkel P. Inflammation and premature aging in advanced chronic kidney disease. Am J Physiol Renal Physiol. 2017;313(4):F938-f950.

7. Stenvinkel P, Larsson TE. Chronic kidney disease: a clinical model of premature aging. Am J Kidney Dis. 2013;62(2):339-51.

8. Walston J, McBurnie MA, Newman A, Tracy RP, Kop WJ, Hirsch CH, Gottdiener J, Fried LP. Frailty and activation of the inflammation and coagulation systems with and without clinical comorbidities: results from the cardiovascular Health study. Arch Intern Med. 2002;162(20):2333-41.

9. Fried LP, Tangen CM, Walston J, Newman AB, Hirsch C, Gottdiener J, Seeman T, Tracy R, Kop WJ, Burke G, et al. Frailty in older adults: evidence for a phenotype. J Gerontol A Biol Sci Med Sci. 2001;56(3):M146-56.

10. Clegg A, Young J, Iliffe S, Rikkert MO, Rockwood K. Frailty in elderly people. Lancet. 2013;381(9868):752-62.

11. Sikka G, Miller KL, Steppan J, Pandey D, Jung SM, Fraser CD III, Ellis C, Ross D, Vandegaer K, Bedja D. Interleukin 10 knockout frail mice develop cardiac and vascular dysfunction with increased age. Exp Gerontol. 2013:48(2):128-35.

12. Walston J, Fedarko $N$, Yang $H$, Leng S, Beamer B, Espinoza S, Lipton A, Zheng $\mathrm{H}$, Becker $\mathrm{K}$. The physical and biological characterization of a frail mouse model. J Gerontol Ser A Biol Med Sci. 2008;63(4):391-8.

13. Jung HW, Kim SW, Yoon SJ, Choi JY, Kim Kl, Kim CH. Associations between frailty, retinal microvascular changes, and cerebral white matter abnormalities in Korean older adults. J Am Geriatr Soc. 2014; 62(11):2209-10.

14. Baker DJ, Wijshake T, Tchkonia T, LeBrasseur NK, Childs BG, Van De Sluis B, Kirkland JL, van Deursen JM. Clearance of p16 Ink4a-positive senescent cells delays ageing-associated disorders. Nature. 2011;479(7372):232.

15. Baker DJ, Childs BG, Durik M, Wijers ME, Sieben CJ, Zhong J, Saltness RA Jeganathan KB, Verzosa GC, Pezeshki A. Naturally occurring p16 Ink4apositive cells shorten healthy lifespan. Nature. 2016;530(7589):184.

16. McAdams-DeMarco MA, Law A, Salter ML, Boyarsky B, Gimenez L, Jaar BG, Walston JD, Segev DL. Frailty as a novel predictor of mortality and hospitalization in individuals of all ages undergoing hemodialysis. J Am Geriatr Soc. 2013;61(6):896-901.

17. McAdams-DeMarco MA, Ying H, Olorundare I, King EA, Haugen C, Buta B, Gross AL, Kalyani R, Desai NM, Dagher NN, et al. Individual frailty components and mortality in kidney transplant recipients. Transplantation. 2017;101(9):2126-32.

18. Lee SW, Lee A, Yu M-Y, Kim SW, Kim KI, Na KY, Chae DW, Chin HJ. Is frailty a modifiable risk factor of future adverse outcomes in elderly patients with incident end-stage renal disease? J Korean Med Sci. 2017:32(11):1800-6.

19. McAdams-DeMarco MA, Law A, Salter ML, Chow E, Grams M, Walston J, Segev DL. Frailty and early hospital readmission after kidney transplantation. Am J Transplant. 2013;13(8):2091-5.

20. Kim HS, Shin DW, Lee WC, Kim YT, Cho B. National screening program for transitional ages in Korea: a new screening for strengthening primary prevention and follow-up care. J Korean Med Sci. 2012;27(Suppl):S70-5.

21. von Haehling S, Morley JE, Coats AJ, Anker SD. Ethical guidelines for publishing in the journal of Cachexia, sarcopenia and muscle: update 2019. J Cachexia Sarcopenia Muscle. 2019;10(5):1143-5.

22. Podsiadlo D, Richardson S. The timed "up \& go": a test of basic functional mobility for frail elderly persons. J Am Geriatr Soc. 1991;39(2):142-8.

23. Savva GM, Donoghue OA, Horgan F, O'regan C, Cronin H, Kenny RA. Using timed up-and-go to identify frail members of the older population. J Gerontol A Biol Sci Med Sci. 2012:68(4):441-6.

24. Jung H-W, Kim S, Jang I-Y, Shin DW, Lee JE, Won CW. Screening value of timed up and go test for frailty and low physical performance in Korean older population: the Korean frailty and aging cohort study (KFACS). Ann Geriat Med Res. 2020;24(4):259.

25. Levey AS, Coresh J, Greene T, Stevens LA, Zhang YL, Hendriksen S, Kusek JW, Van Lente F. Using standardized serum creatinine values in the modification of diet in renal disease study equation for estimating glomerular filtration rate. Ann Intern Med. 2006;145(4):247-54.

26. Levey AS, Stevens LA, Schmid CH, Zhang YL, Castro AF 3rd, Feldman HI, Kusek JW, Eggers P, Van Lente F, Greene T, et al. A new equation to estimate glomerular filtration rate. Ann Intern Med. 2009;150(9):604-12.

27. Fine JP, Gray RJ. A proportional hazards model for the subdistribution of a competing risk. J Am Stat Assoc. 1999:94(446):496-509.

28. Franceschi C, Campisi J. Chronic inflammation (inflammaging) and its potential contribution to age-associated diseases. J Gerontol A Biol Sci Med Sci. 2014;69(Suppl 1):S4-9.

29. Vel Szic KS, Declerck K, Vidaković M, Berghe WV. From inflammaging to healthy aging by dietary lifestyle choices: is epigenetics the key to personalized nutrition? Clin Epigenetics. 2015;7(1):33.

30. Yaffe K, Kanaya A, Lindquist K, Simonsick EM, Harris T, Shorr RI, Tylavsky FA, Newman AB. The metabolic syndrome, inflammation, and risk of cognitive decline. JAMA. 2004:292(18):2237-42.

31. Hawkins MS, Sevick MA, Richardson CR, Fried LF, Arena VC, Kriska AM Association between physical activity and kidney function: National Health and nutrition examination survey. Med Sci Sports Exerc. 2011;43(8):1457-64.

32. Jung HW, Kim Kl. Multimorbidity in older adults. J Korean Geriatr Soc. 2014; 18(2):65-71.

33. Ballew SH, Chen Y, Daya NR, Godino JG, Windham BG, McAdams-DeMarco M, Coresh J, Selvin E, Grams ME. Frailty, kidney function, and polypharmacy: the atherosclerosis risk in communities (ARIC) study. Am J Kidney Dis. 2017; 69(2):228-36. 
34. Sutaria A, Liu L, Ahmed Z. Multiple medication (polypharmacy) and chronic kidney disease in patients aged 60 and older: a pharmacoepidemiologic perspective. Ther Adv Cardiovasc Dis. 2016;10(4):242-50.

35. Rosario BL, Rosso AL, Aizenstein HJ, Harris T, Newman AB, Satterfield S, Studenski SA, Yaffe K, Rosano C, Health ABCS. Cerebral white matter and slow gait: contribution of Hyperintensities and Normal-appearing parenchyma. J Gerontol A Biol Sci Med Sci. 2016;71(7):968-73.

36. Reese PP, Cappola AR, Shults J, Townsend RR, Gadegbeku CA, Anderson C, Baker JF, Carlow D, Sulik MJ, Lo JC, et al. Physical performance and frailty in chronic kidney disease. Am J Nephrol. 2013;38(4):307-15.

37. Jang I-Y, Jung H-W, Park H, Lee CK, Yu SS, Lee YS, Lee E, Glynn RJ, Kim DH. A multicomponent frailty intervention for socioeconomically vulnerable older adults: a designed-delay study. Clin Interv Aging. 2018; In press.

38. Cesari M, Vellas B, Hsu F-C, Newman AB, Doss H, King AC, Manini TM, Church T, Gill TM, Miller ME. A physical activity intervention to treat the frailty syndrome in older persons-results from the LIFE-P study. J Gerontol A Biol Sci Med Sci. 2014;70(2):216-22.

39. Cameron ID, Fairhall N, Langron C, Lockwood K, Monaghan N, Aggar C, Sherrington C, Lord SR, Kurrle SE. A multifactorial interdisciplinary intervention reduces frailty in older people: randomized trial. BMC Med. 2013;11:65.

40. Montero-Odasso M, Almeida QJ, Bherer L, Burhan AM, Camicioli R, Doyon J, Fraser S, Muir-Hunter S, Li KZH, Liu-Ambrose T, et al. Consensus on shared measures of mobility and cognition: from the Canadian consortium on Neurodegeneration in aging (CCNA). J Gerontol A Biol Sci Med Sci. 2019; 74(6):897-909.

41. Cruz-Jentoft AJ, Bahat G, Bauer J, Boirie Y, Bruyère O, Cederholm T, Cooper C, Landi F, Rolland Y, Sayer AA, et al. Sarcopenia: revised European consensus on definition and diagnosis. Age Ageing. 2018:48:16-31.

42. Bischoff HA, Stahelin HB, Monsch AU, Iversen MD, Weyh A, von Dechend M, Akos R, Conzelmann M, Dick W, Theiler R. Identifying a cut-off point for normal mobility: a comparison of the timed 'up and go' test in community-dwelling and institutionalised elderly women. Age Ageing. 2003;32(3):315-20.

43. S-w K, Jung H-W, Kim C-H, K-i K, Chin HJ, Lee H. A new equation to estimate muscle mass from creatinine and cystatin C. PLoS One. 2016;11(2): e0148495.

44. Baxmann AC, Ahmed MS, Marques NC, Menon VB, Pereira AB, Kirsztajn GM, Heilberg IP. Influence of muscle mass and physical activity on serum and urinary creatinine and serum cystatin C. Clin J Am Soc Nephrol. 2008;3(2): $348-54$

\section{Publisher's Note}

Springer Nature remains neutral with regard to jurisdictional claims in published maps and institutional affiliations.

Ready to submit your research? Choose BMC and benefit from:

- fast, convenient online submission

- thorough peer review by experienced researchers in your field

- rapid publication on acceptance

- support for research data, including large and complex data types

- gold Open Access which fosters wider collaboration and increased citations

- maximum visibility for your research: over $100 \mathrm{M}$ website views per year

At $\mathrm{BMC}$, research is always in progress.

Learn more biomedcentral.com/submissions 